\title{
Noise in an intensive care unit
}

\author{
Andrea Salandin a , Jörg Arnold b, Oliver Kornadt b \\ ${ }^{a}$ CTF - Centro de Tecnologías Físicas, Universidad Politécnica de Valencia, c/Vera s/n, 46022 Valencia, Spain \\ ${ }^{b}$ Bauhaus-University Weimar, Coudraystraße 11a, 99421 Weimar, Germany
}

(Received 18 July 2009; revised 12 July 2011; accepted 5 October 2011)

\section{Copyright Notice}

Copyright 2011 Acoustical Society of America. This article may be downloaded for personal use only. Any other use requires prior permission of the author and the Acoustical Society of America.

The following article appeared in The Journal of the Acoustical Society of America 130, 3754 (2011) and may be found at http://dx.doi.org/10.1121/1.3655884.

\begin{abstract}
Patients and staff in hospitals are exposed to a complex sound environment with rather high noise levels. In intensive care units, the main noise sources are hospital staff on duty and medical equipment, which generates both operating noise and acoustic alarms. Although noise in most cases is produced during activities for the purpose of saving life, noise can induce significant changes in the depth and quality of sleep and negatively affect health in general. Results of a survey of hospital staff are presented as well as measurements in two German hospital wards: a standard two-bed room and a special Intermediate Care Unit (IMC-Unit), each in a different Intensive Care Unit (ICU). Sound pressure data were collected over a 48 hour period and converted into different levels (LAFeq, LAFmax, LAFmin, LAF 5\%), as well as a rating level LAr, which is used to take tonality and impulsiveness into account. An analysis of the survey and the measured data, together with a comparison of thresholds of national and international regulations and standards describe the acoustic situation and its likely noise effects on staff and patients.
\end{abstract}




\section{Introduction}

Patients and staff in hospitals are exposed to rather high noise levels. [1]-[3] Furthermore, it seems that both day and night-time noise has been increasing in hospitals since the $1960^{\text {'s }}{ }^{[4]}$, due to the increase in the use of medical devices. In intensive care units, the general high noise level results from three factors: a high level of background noise, staff activity, and acoustic alarms of monitoring and therapeutic devices. [5]-[8]

The improvement in medicine and in medical equipment has resulted in an increased number and variety of very specialised equipment used in intensive care units. These machines produce an acoustic cocktail of alarm signals. [1],[9] Many non-vital alarms have an unnecessarily high sound intensity, which means that vital alarms could go unnoticed.[2],[10] Often, the staff working on an ICU cannot adjust the volume of alarms.

Additionally, the staff itself is an important source of noise. In performing their work, they produce noise either automatically (for example by walking around) or accidentally (for example by dropping metallic objects on the floor). [2] Patients often consider the noise resulting from staff activity to be a major stress factor. [11]-[14]

Usually, the materials used to cover walls and ceilings are highly sound-reflective and have low acoustical absorption, resulting in build up of reverberant noise. Due to the long reverberation, resulting from the required use of special materials in intensive care units, the problems associated with noise pollution for personnel and patients are further exacerbated.

A high sound level in the wards conflicts with patients' needs for peace and quiet. [3] As a result of the high demand for staff and medical devices in intensive care units, the special noise environment of the ICU is a permanent influence on multiple health factors for patients, including effects on the cardiovascular system and the quality of sleep. Sudden and impulsive noises exceeding the background noise level by more than $30 \mathrm{~dB}(\mathrm{~A})$ (such as an alarm activation) can cause an increase in heart rate, breathing rate and oxygen requirements. [14]-[18]

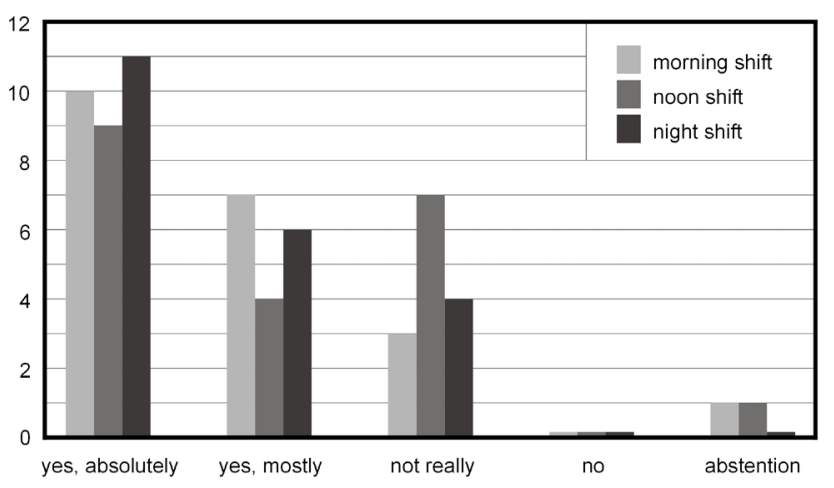

Fig. 1. Question: Do you find the noise situation in the work place uncomfortable or disruptive?
Noise also can induce important changes in sleep depth and a subjective deterioration of sleep quality. [19],[20] $\mathrm{A}$ noise with a sound pressure level of $60 \mathrm{~dB}(\mathrm{~A})$ already has a high probability of waking healthy people, whereas elderly and ill persons are potentially more sensitive to sound disturbance. [6],[21],[22] However, the sound pressure level alone is not sufficient in order to describe the effect of noise on sleep disruption. The impulsivness, the information content as well as the frequency composition of noise also has substantial influence. [23] But most of all, noise with a strong difference between baseline and peak causes people to wake. This implies steady and broad-band noise acts as masking and can hide quieter impulsive sounds. Because an ICU representing a situation with a high background noise, in these investigating a sound pressure level of $70 \mathrm{~dB}(\mathrm{~A})$ has been assumed as a potential wake-up threshold according to Refs. [24] and [25], provided that the noise significantly exceeds the given background level.

For hospital staff, the combination of workload, fatigue, and a sense of responsibility can cause high-stress situations. Noise potentially increases existing psychological stress and can cause loss of concentration. [1],[26],[27]

This paper presents an investigation based on a survey and measurements of noise in a two-bed room and a four-bed Intermediate Care Unit (IMC-Unit) in a German hospital.

\section{Staff survey}

A survey of the acoustical situation was conducted to gather information on staff members' subjective assessment of noise in intensive care units. 21 hospital staff members, including 14 nurses and 7 doctors, completed the survey. Fig. 1 shows that more than $80 \%$ of the staff during all 3 shifts felt disturbed by noise, with slightly higher reported values in the morning and night shifts. $76 \%$ of the interviewees reported being disturbed by noise generated by the operation and alert sounds of medical devices, as well as phones and other IT-equipment (Fig. 2). High noise levels influence people's ability to communicate and concentrate.

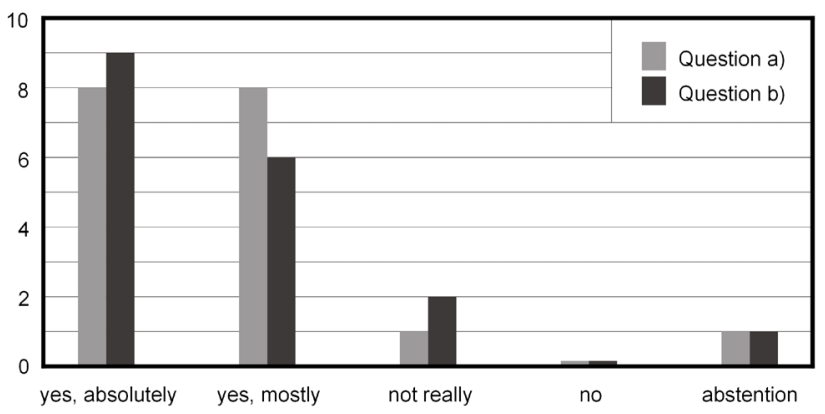

Fig. 2. Question a): Do operating noises and alerts of medical devices bother you?

Question b): Do noises from phones or other IT-equipment bother you? 
A similar survey in a Swedish ICU ${ }^{[1]}$ concluded that more than $90 \%$ of the staff felt that they might be negatively influenced by noise in the workplace. In a haematological cancer unit in a new building in Maryland, a survey [28] found that $83.3 \%$ of nurses were dissatisfied with the effect that noise had on their ability to communicate with health care providers, and $91.7 \%$ were dissatisfied with their ability to hear clinical conversation during their morning rounds.

\section{Description of measurements}

Measurements of sound pressure levels were taken in representative locations in an Intensive Care Unit. Additionally, sound pressure levels of the most important and frequently used medical devices were analysed.

The sound pressure level was measured by an integrated acoustic-level-analyser (DIN EN 60651standard [29] precision class 1) through a condenser microphone with spherical characteristics. Using the DIN EN 60651, one representative location was chosen in each enclosure. The measured data were recorded over a 48hour period (a total of 6 complete work-shifts) with "fast" as well as "impulse" integration time and the spectrum was Aweighted. The energy equivalent continuous level ( $\mathrm{L}_{\mathrm{AFeq}}$ ), the maximum level ( $\mathrm{L}_{\mathrm{AFmax}}$ ), the reference for high levels ( $\mathrm{L}_{\mathrm{AF}} 5 \%$ ), the minimum level ( $\mathrm{L}_{\mathrm{AFmin}}$ ), as well as the rating level ( $\mathrm{L}_{\mathrm{Ar}}$ ) were measured and calculated, respectively. The rating level according to DIN 45645 (Part 2) [30] was calculated as

$$
\begin{aligned}
& L_{A r}=10 \cdot \log \left[\frac{1}{T_{r}} \cdot \sum_{i=1}^{n} T_{i} \cdot 10^{0.1 \cdot\left(L_{A e q, i}+K_{I, i}+K_{T, i}\right)}\right] \\
& \text { where: } \\
& \mathrm{T}_{\mathrm{r}} \quad \ldots \quad \text { evaluation time range } \\
& \text { (in our measurement 8h) } \\
& \mathrm{T}_{\mathrm{i}} \quad \ldots \quad \text { time segment (trigger: } 110 \mathrm{~ms} \text { ) } \\
& \text { n } \quad \ldots \quad \text { number of time segments } \\
& \text { LAFeq,i ... A A-weighted energy equivalent sound } \\
& \text { pressure level "fast mode" } \\
& \text { LAleq,i } \quad \ldots \quad \text { A-weighted energy equivalent sound } \\
& \text { pressure level "impulse mode" } \\
& \mathrm{K}_{\mathrm{I}, \mathrm{i}} \quad \ldots \quad \text { coefficient for impulsiveness } \\
& \left(\mathrm{K}_{\mathrm{I}, \mathrm{i}}=\mathrm{L}_{\mathrm{Aleq}, \mathrm{i}}-\mathrm{L}_{\mathrm{AFeq}, \mathrm{i}}\right) \\
& \mathrm{K}_{\mathrm{T}, \mathrm{i}} \quad \ldots \quad \text { coefficient for tonality. }
\end{aligned}
$$

This is a specific level for workplaces for an eight-hour shift. The coefficient for tonality is $\mathrm{K}_{\mathrm{T}}=3 \mathrm{~dB}$ or $6 \mathrm{~dB}$ if a tone is clearly audible over the background noise. A simple tone in a third-octave band analysis is audible if the level is $3 \mathrm{~dB}$ higher than the continuous level. The coefficient for impulsiveness $\mathrm{K}_{\mathrm{I}}$ can be calculated as the difference between $\mathrm{L}_{\text {Aleq }}$ and $\mathrm{L}_{\mathrm{AFeq}}$. The advantage of the rating level $\mathrm{L}_{\mathrm{Ar}}$ is that it can be used to assess the psychological effects of tonality and impulsiveness. In the German Regulation for Places of Work [31] and the VDI $2058{ }^{[32]}$ maximum permitted values on $\mathrm{L}_{\mathrm{Ar}}$ are defined. This will be discussed in section 4 in detail.
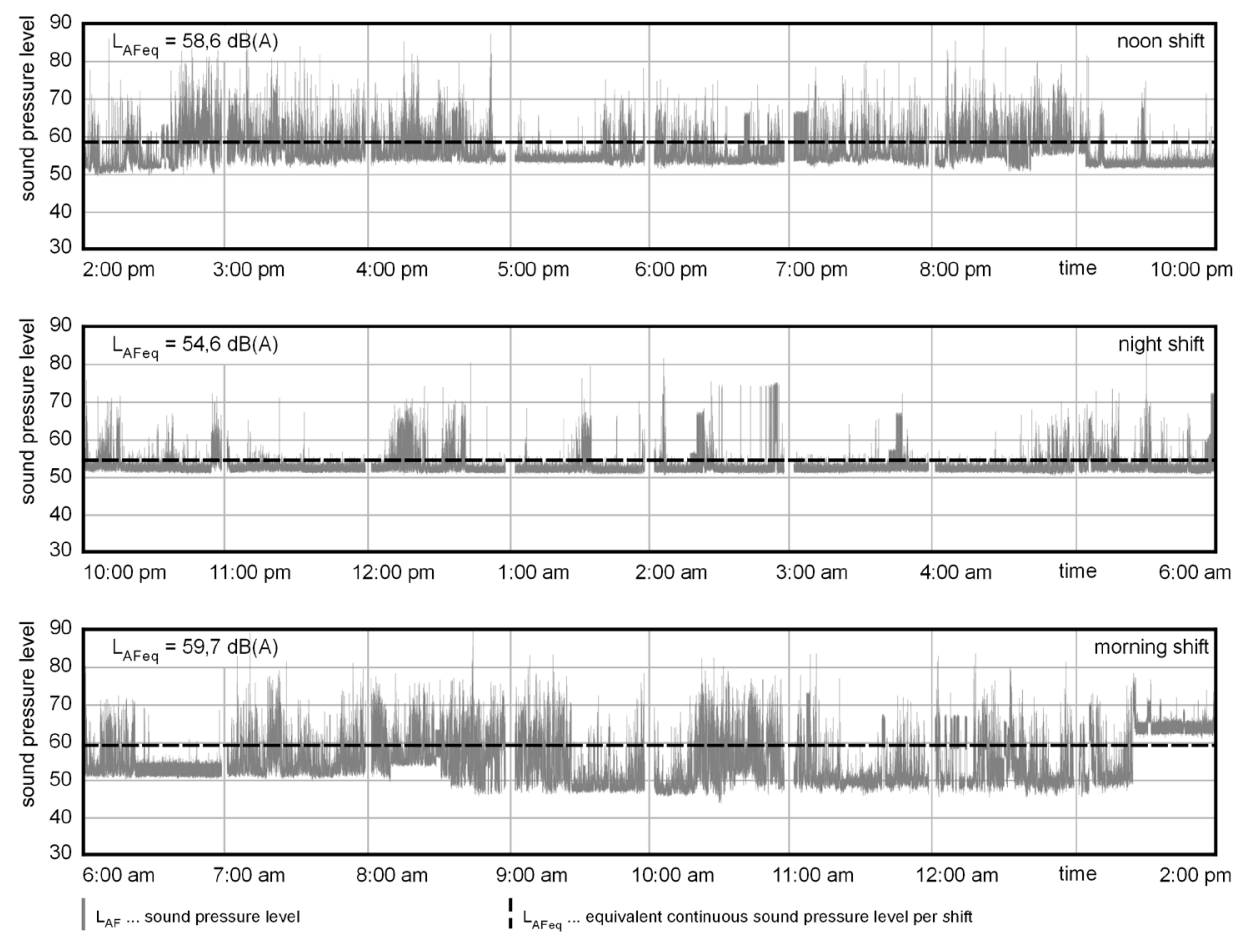

Fig. 3. Course of the sound pressure level over 24 hours in a two-bed ward 


\section{Results and analysis of the data measured in wards}

Fig. 3 and Fig. 4 describe the acoustic situation and show the evolution of the sound pressure level during a 24hour period starting at two pm. This included three 8-hourshifts in a two-bed ward and in a IMC-Unit, respectively.

The IMC-Unit is a special four-bed ward for patients that need special observations by hospital staff after serious operations for a maximum period of 24 hours. Normally, these patients do not need as much medical equipment as other patients in an ICU. For example, they do not need artificial respiration. Consequently, an IMC has fewer medical devices as potential sound sources, and less noise compared to a normal ward such as the one containing the two-bed room.
For each shift (noon, night and morning shift) the equivalent continuous sound pressure level LAFeq is calculated and added in the figures.

The sound pressure level $\mathrm{L}_{A F}$ in the two-bed-ward varies dramatically, from a low of $44 \mathrm{~dB}(\mathrm{~A})$ to a high of $95 \mathrm{~dB}(\mathrm{~A})$. The background noise level is about $50 \mathrm{~dB}(\mathrm{~A})$, without any significant reduction during the night shift. Typically, there are periods of 10 to 60 minutes showing an increase of the background noise level of about 5 to $10 \mathrm{~dB}(\mathrm{~A})$ due to doctors' consultations, shift changes, relatives' visits or alarms from medical devices.

$\mathrm{L}_{\mathrm{AFeq}}$ is at about $59 \mathrm{~dB}(\mathrm{~A})$ during the day shifts and reduced by about $4 \mathrm{~dB}(\mathrm{~A})$ during the night shifts. Nevertheless, this reduced night-time level of LAFeq of $55 \mathrm{~dB}(\mathrm{~A})$ is still a very high night level.
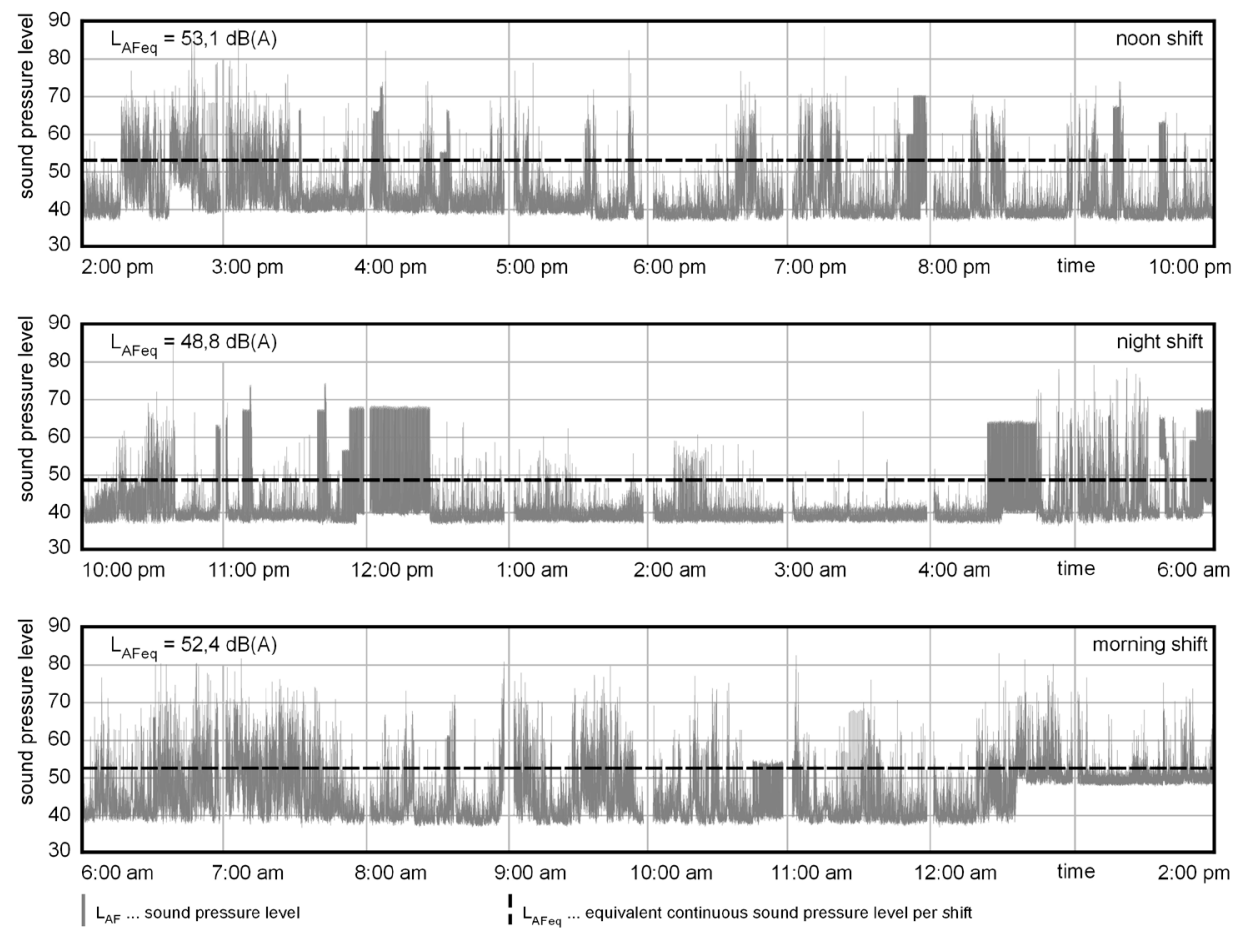

Fig. 4. Course of the sound pressure level over 24 hours in an IMC-unit

The sound pressure level LAF in the IMC-unit varies from $36 \mathrm{~dB}(\mathrm{~A})$ to $104 \mathrm{~dB}(\mathrm{~A})$ (Fig. 7) and exceeds even the highest values observed in the two-bed room. In the IMC-unit the background noise level is rather constant at $39 \mathrm{~dB}(\mathrm{~A})$ and significantly lower than in the two-bed ward.

$\mathrm{L}_{\mathrm{AFeq}}$ is at about $53 \mathrm{~dB}(\mathrm{~A})$ during the day shifts and is reduced by about $4 \mathrm{~dB}(\mathrm{~A})$ during the night shift. It is approximately $5 \mathrm{~dB}(\mathrm{~A})$ lower than in the two-bed room. It is similar to the two-bed room in that there are periods with dramatic increase in the background noise level of typically 5 to $10 \mathrm{~dB}(\mathrm{~A})$. These periods often start with a serious alarm, which has a peak of up to $90 \mathrm{~dB}(\mathrm{~A})$ with a small frequency range of $1.000 \mathrm{~Hz}$, for example. After the alarm, there is typically the noise of working hospital staff. These peaks are an important factor in the quantity, distribution and fragmentation of patient sleep and stress. [19],[24],[33]

The incidence of peaks was investigated more in detail: all peaks exceeding $70 \mathrm{~dB}(\mathrm{~A})$ (a threshold which we regard as a reasonable wake-up threshold for healthy people) and with a significantly sound elevation above the background level were registered. Two peaks within a period of 4 minutes were considered as one event. The distribution of such peaks every hour for both wards is shown in Fig. 5. 


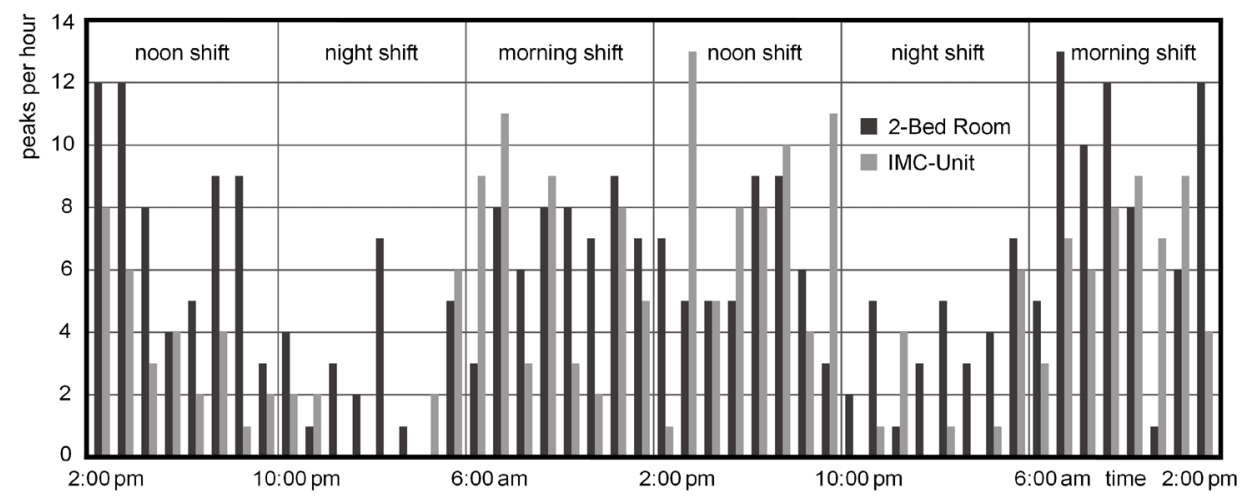

Fig. 5. Distribution of peaks in the two-bed ward and the IMC-unit

In the two-bed ward, 287 events were registered - an average of 6 peaks per hour. However, the distribution of peaks during day is uneven. There are more peaks during the day and fewer at night. In the two-bed ward, in only 7 of the 48 hours were there fewer than 2 peaks, and only one with none. In the IMC-unit, 218 events were measured, producing an average of 4.5 peaks per hour and a similar distribution. In most cases, fewer than 2 events per hour occurred during the night shift $(10: 00 \mathrm{pm}-6: 00 \mathrm{am})$. Nevertheless, in the first (second) night shift, there were still 12 (13) events with a noise peak level of more than $70 \mathrm{~dB}(\mathrm{~A})$. During 48 hours there were only 7 hours without any peaks over $70 \mathrm{~dB}(\mathrm{~A})$.
To make further investigations, the parameters $\mathrm{L}_{\mathrm{AFmax}}$, LAFmin, LAF 5\% were calculated for one hour reference periods. The equivalent continuous level $\mathrm{L}_{\mathrm{AFeq}}$ and the rating level $\mathrm{L}_{\mathrm{Ar}}$ were calculated by using reference periods of 8 hours, or one full shift. Because noise rather often includes sounds from alerts, which are marked by a narrow frequency band, a bias of $3 \mathrm{~dB}$ for tonality $\left(\mathrm{K}_{\mathrm{T}, \mathrm{i}}=3 \mathrm{~dB}\right)$ was applied. For a 48 hour period, the results for the two-bed ward (IMC-unit) are presented in Fig. 6 (Fig. 7).

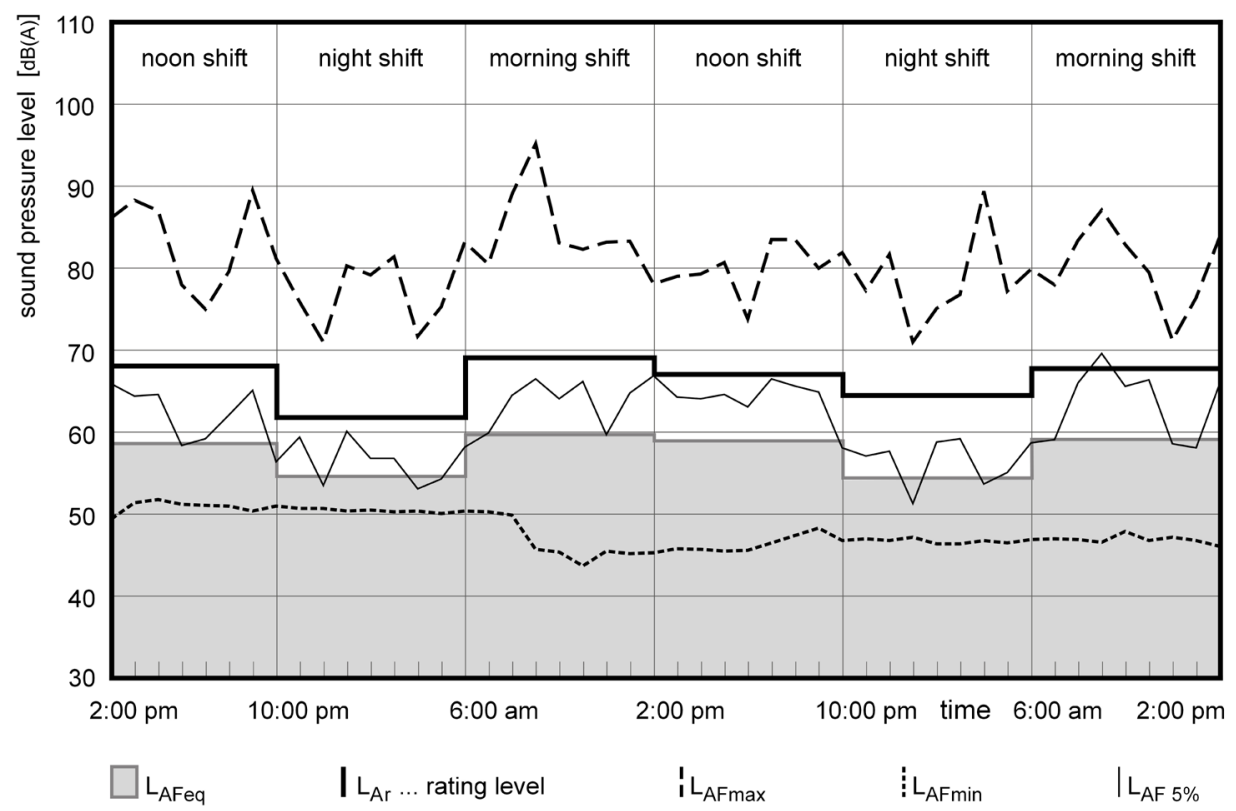

Fig. 6. $L_{A F e q}, L_{A F m a x} L_{A F} 5 \%, L_{A F m i n}, L_{A r}$ in the two-bed ward

In all shifts, in the two-bed room LaFmax exceeds the high value of $71 \mathrm{~dB}(\mathrm{~A})$ and goes up to as high as $95 \mathrm{~dB}(\mathrm{~A})$. To investigate the incidence of levels above a threshold, percentile levels are very helpful. [34] Because the reference for high levels, LAF $5 \%$ is much lower than LAFmax, sound pressure levels approaching LAFmax are rather seldom. Furthermore, it is remarkable that even the minimum sound pressure level lies at rather high values, between $45 \mathrm{~dB}(\mathrm{~A})$ and $50 \mathrm{~dB}(\mathrm{~A})$. 


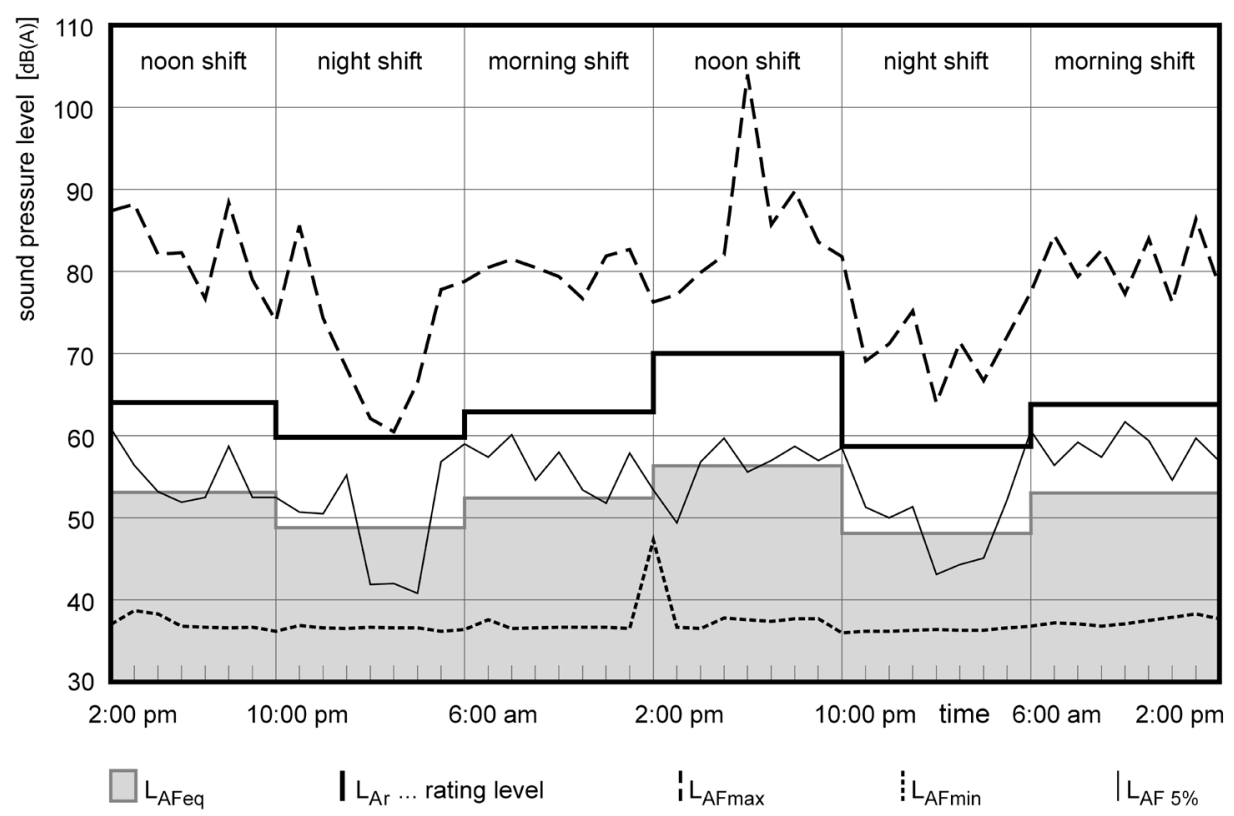

Fig. 7. $L_{A F e q}, L_{A F m a x}, L_{A F} 5 \%, L_{A F m i n} L_{A r}$ in the IMC-unit

$\mathrm{L}_{\mathrm{AFeq}}$ varies from $54 \mathrm{~dB}(\mathrm{~A})$ to $60 \mathrm{~dB}(\mathrm{~A})$ in all investigated shifts. Even during night time, the level is above $54 \mathrm{~dB}(\mathrm{~A})$. This value dramatically exceeds the World Health Organisation (WHO) [35] recommended LAFeq level of $35 \mathrm{~dB}(\mathrm{~A})$ for day-time and $30 \mathrm{~dB}(\mathrm{~A})$ for night time, respectively. This finding agrees with investigations on other ICU's [20],[34],[36] where significant exceedances of WHO thresholds were also determined. According to the American Environmental Protection Agency (EPA) [37] noise levels above $45 \mathrm{~dB}(\mathrm{~A})$ should be avoided in hospitals. The measured data exceeds even this value during day and night shifts.

The rating value, $L_{A r}$ is between $62 \mathrm{~dB}(\mathrm{~A})$ and $69 \mathrm{~dB}(\mathrm{~A})$ during these 6 shifts. In VDI 2058-3 [32] the following thresholds for $L_{A r}$ are determined:

(1) $L_{A r}<55 d B(A)$, for mainly intellectual or mental work

(2) $L_{A r}<70 \mathrm{~dB}(\mathrm{~A})$, for simple or mainly mechanised office work and comparable activities

(3) $\mathrm{L}_{\mathrm{Ar}}<85 \mathrm{~dB}(\mathrm{~A})$, for all other activities

Work performed by nurses is probably categorized as both mechanised and intellectual work, while work performed by doctors is foremost intellectual work. Since $\mathrm{L}_{\mathrm{Ar}}$ exceeds the limit of $55 \mathrm{~dB}(\mathrm{~A})$ during all investigated shifts according to VDI 2058-3, the noise level is too high to safely perform intellectual or mental work.

In the IMC-unit the maximum level $\mathrm{L}_{\mathrm{AFmax}}$ varies much more and is typically slightly lower than in the two-bed room. The minimum level LAFmin is significantly lower than in the two-bed room. This is clearly a result of the lower number of medical devices used in the IMC-unit. Despite this, the minimum level is still above $35 \mathrm{~dB}(\mathrm{~A})$ and even during night time, $\mathrm{L}_{\mathrm{AFeq}}$ is above $48 \mathrm{~dB}(\mathrm{~A})$. Thus, the maximum $\mathrm{L}_{\mathrm{AFeq}}$ limit of $35 \mathrm{~dB}(\mathrm{~A})$ established by the WHO is considerably exceeded.
Even the EPA threshold of $45 \mathrm{~dB}(\mathrm{~A})$ is surpassed during day and night shifts.

The rating level, LAr used to assess the acoustical conditions for the staff on duty is only slightly lower in the IMC-unit in comparison to the two-bed ward. But, this level is still higher than $60 \mathrm{~dB}(\mathrm{~A})$ and thus, according to VDI 20583 [32] is still high enough to negatively affect intellectual work.

\section{Conclusions}

The investigation comprises a survey of hospital staff and the measurement of different noise levels in a standard ward two-bed room as well as in an Intermediate Care Unit of an Intensive Care Unit.

The survey showed that hospital staff (nurses and doctors equally) are stressed and disturbed by the complex mixture of different sounds produced by various alarms, by the operating sounds of medical devices, by the activities of the hospital staff itself, and by conversations of staff and relatives. These noises affect the ability to concentrate and to comprehend conversations.

Noise measurements show that LAFeq varies dramatically from $44 \mathrm{~dB}(\mathrm{~A})$ to $95 \mathrm{~dB}(\mathrm{~A})$ in a two-bed room and $36 \mathrm{~dB}(\mathrm{~A})$ to $104 \mathrm{~dB}(\mathrm{~A})$ in an IMC-unit. In all shifts, the $\mathrm{L}_{\mathrm{AFmax}}$ exceeds values between $71 \mathrm{~dB}(\mathrm{~A})$ and $95 \mathrm{~dB}(\mathrm{~A})$ in the two-bed room and between $60 \mathrm{~dB}(\mathrm{~A})$ and $104 \mathrm{~dB}(\mathrm{~A})$ in the IMC-unit. Since peaks with a sound pressure level above $70 \mathrm{~dB}(\mathrm{~A})$ cause healthy people to wake up and can produce stress and physical effects, the incidence of peaks exceeding the threshold of $70 \mathrm{~dB}(\mathrm{~A})$ was investigated more in detail. Over 48 hours, 287 (218) events were registered in a two-bed room (IMC-unit) with an average of 6 (4.5) peaks per hour. Even in the situation with the fewest noises (at night in the IMC-unit) there were still 12 events with a peak of over $70 \mathrm{~dB}(\mathrm{~A})$. 
The rating level $L_{A r}$ was also investigated. This level takes the psychological effects of tonality and impulsiveness into account and is used in Germany to assess the acoustic situation in work-places. The analysis shows that across all shifts in the two-bed room as well as in the IMC-unit, the measured rating level $\mathrm{L}_{\mathrm{Ar}}$ lies between $60 \mathrm{~dB}(\mathrm{~A})$ and $69 \mathrm{~dB}(\mathrm{~A})$, which is much higher than the recommended level for work that is mainly intellectual. However, for simple, mainly mechanised office work and comparable activities, the threshold is reached.

In order to reduce the noise exposure on staff and patients, several active and passive measures are available. As acoustical alarms are much more effective than optical signals, there is no option in the near future of totally avoiding them. An improvement could be achieved through the standardisation and coordination of alarm signals and their volumes by producers of medical devices. [38] Through a thoughtful acoustical design of alarms and signals, the relative medical relevance of a signal could be better identified. In addition, research should be undertaken to establish how the operating noises of necessary medical devices (like mechanical ventilation devices) can be reduced.

In order to achieve a reduction of noise related to staff activities, education campaigns should be the first step, in order to make staff conscious of their own noise production. Following that, changes in working procedures should be integrated. The final goal is conscious behaviour and better adaptation to the situation. Examples are the use of an appropriate tone of speech and switching off technical devices such as radios and televisions. Dimming lights at night also encourages quiet behaviour. [39] Furthermore, designated "quiet times" (for example, at night) during which noisy activities would be prohibited, could also be implemented. Pilot projects using these measures have shown to produce positive effects in reducing noise. [20],[27],[39],,[40],[41]

A passive noise reduction measure is to minimize the reverberation time in the ICU-wards. For the IMC-Unit we calculate a very high mid-range frequency reverberation time of $1.8 \mathrm{~s}$ (volume of $125 \mathrm{~m}^{3}$, linoleum flooring, special sanitary wallpaper for walls and ceiling), even taking the absorption by 4 patients and furniture into account. In a similar room, the suggested reverberation time for spoken communication is $0.6 \mathrm{~s}$. We see here great potential for improvement. Preliminary research on the use of special sound-absorbing materials in ICU's confirms the positive impacts of this measure. [28],[42]

Another cost-effective alternative is the use of earplugs or earmuffs, which has also been subjected to research. [43],[44] It should be noted that this measure only applies to hospital patients and not to hospital staff.

Finally, the use of sound masking systems (producing random noises, ocean sounds or special music) should be considered. These don't reduce noise levels, but, by reducing the distance between the background noise level and the level of disturbing noises, they reduce the overall level of disruption. Preliminary studies of these technologies, with a view to improving sleep quality, have likewise been performed. [25],[45]

In conclusion, this survey could be seen as the first step in a more complete study across several European Countries with the aim to provide a European overview of the noise situation in ICU's. In this context, selected noise mitigation measures should be tested in an interdisciplinary approach involving doctors and acoustical experts. First contacts have been taken with an Italian hospital (Ospedale Generale di Bolzano, Bolzano) and a Spanish hospital (Hospital del Sureste, Arganda del Rey, Madrid).

\section{Acknowledgments}

We would like to thank the German Academic Exchange Service (DAAD) for the financial support.

\section{References}

[1] E.E. Ryherd, K. Persson Waye and L. Ljungkvist, "Characterizing noise and perceived work environment in a neurological intensive care unit," J. Acoust. Soc. Am. 123 (2), 747-756 (2008)

[2] J. E. West, "Noise in hospitals: Effects and cures," Annual Harold W. Gegenheimer Lecture Series on Innovation (2008)

[3] D. Schrader and N. Schrader, "Lärm auf Intensivstationen und dessen Auswirkungen auf Patienten und Personal, Teil 1 Noise in intensive care units and its effects on patients and staff, Part 1," Intensiv - Fachzeitschrift für Intensivpflege und Anästhesie 9 (3), 96-106 (2001)

[4] J. E. West and I. Busch-Vishniac, "What do we know about noise in hospitals," J. Acoust. Soc. Am. 118 (3),1949-1949 (2005)

[5] I. J. Busch-Vishniac, J. E. West, C. Barnhill, T. Hunter, D. Orellana and R. Chivukula, "Noise levels in Johns Hopkins Hospital," J. Acoust. Soc. Am. 118 (6), 3629-3645 (2005)

[6] R. J. Aitken, "Quantitative noise analysis in a modern hospital," Archives of Environmental Health 37 (6), 361-364 (1982)

[7] A. Vinodhkumaradithyaa, M. Srinivasan, I. Ananthalakshmi, D. Pradeep Kumar, R.V. Jeba Rajasekhar, Tennyson Daniel and P. Thirumalaikolundusubramanian, "Noise levels in a tertiary care hospital," Noise and Health 10 (38), 11-13 (2008)

[8] E. Ryherd and K. P. Waye, "Describing the sound environment of the neurological intensive care unit and personnel response," J. Acoust. Soc. Am. 123 (5), 3668-3668 (2008)

[9] A. Deller, B. Schüle, F. Konrad and J. Kilian, "Alarme durch medizinisch-technische Geräte auf der operativen Intensivstation: eine prospective Studie - Alarms of medicaltechnical devices on operative intensive care units: a prospective study," Anaesthesie, Intensivtherapie, Notfallmedizin 23, 238-243 (1988)

[10] D. J. MacKenzie and L. Galbrun, "Noise levels and noise sources in acute care hospital wards," Building Services Engineering Research and Technology 28 (2), 117-131 (2007) 
[11] B. Burzel, H. Benzer, C. Gollner and G. Pauser, "Psychische Stressfaktoren in der Intensivmedizin - Psychological stress factors on intensive care," Anaesthesist 31, 693-698 (1982)

[12] B. Allaouchiche, F. Duflo, R. Debon, A. Bergeret and D. Chassard, "Noise in the postanaesthesia care unit," Br. J. Anaesth. 88, 369-73 (2002)

[13] L. S. Goodfriend, "Noise in hospitals redux," J. Acoust. Soc. Am. 119 (5), 3327-3327 (2006)

[14] H. Xie, J. Kang and G. Mills, "The impact of noise on patients' sleep and the effectiveness of noise reduction strategies in intensive care units," Critical Care 13 (2), electronic version (2009)

[15] M. Spreng, "Risikofaktor Lärm: physiologische Aspekte Noise as risk: physiological aspects," Therapiewoche 34, 3765-3772 (1984)

[16] L. Whalen, "Noise in the intensive care setting," Canadian Critical Care Nursing Journal Feb/Mar, 9-10 (1992)

[17] A. Connor and E. Ortiz, "Staff solutions for noise reduction in the workplace," The Permanent Journal 13 (4), 23-27 (2009)

[18] W. E. Morrison, E. Haas, D. Shaffner, E. S. Garrett and J. Fackler, "Noise, stress, and annoyance in a paediatric intensive care unit," Critical Care Medicine 31(1), 113-119 (2003)

[19] S. Parthasarathy and M. J. Tobin, "Sleep in the intensive care unit," Intensive Care Med 30, 197-206 (2003)

[20] R. J. Pugh, C. Jones and R.D. Griffiths, "The impact of noise in the intensive care unit," Yearbook of Intensive Care and Emergency Medicine, Berlin and Heidelberg, Springer, 2007, 942-949

[21] Umweltbundesamt - German Federal Environment Agency, "Lärmbekämpfung 1988 - Noise control 1988," Erich Schmidt Edition, Berlin, 1989

[22] C. Maschke, K. Hecht and U. Wolf, "Nocturnal awakenings due to aircraft noise. Do wake-up reactions begin at sound level 60 dB(A)?," Noise and Health 6 (24), 21-33 (2004)

[23] R. Guski, "Lärm. Wirkungen unerwünschter Geräusche Noise. Effects of undesired sounds," Bern, Hand Huber Edition, 1987

[24] J. Y. Gabor, A. B. Cooper, S. A. Crombach, B. Lee, N. Kadikar, H. E. Bettger and P. J. Hanly, "Contribution of the intensive care unit environment to sleep disruption in mechanically ventilated patients and healthy subject," Am. J. Respir. Crit. Care Medicin 167, 708-715 (2003)

[25] M. L. Stanchina, M. Abu-Hijleh, B. K. Chaudhry, "The influence of white noise on sleep in subjects exposed to ICU noise," Sleep Medicine 6 (5), 423-428 (2005)

[26] M. Topf, "Effects of personal control over hospital noise on sleep," Research in Nursing and Health 15, 19-28 (1992)

[27] D. M. Kahn, T. E. Cook, C. C. Carlisle, D. L. Nelson, N. R. Kramer and R. P. Millman, "Identification and modification of environmental noise in an ICU setting," Chest 114, 535-540 (1998)

[28] M. MacLeod, J. Dunn, I. J. Busch-Vishniac, J. E. West and A. Reedy, "Quieting Weinberg 5C: A case study in hospital noise control," J. Acoust. Soc. Am. 121 (6), 3501-73508 (2007)

[29] DIN 60651, "Schallpegelmesser - Sound level meters," Beuth Edition, 1994
[30] DIN 45645 - Part 2, "Ermittlung von Beurteilungspegeln aus Messungen - Calculation of rating levels from recorded data," Beuth Edition, 1997

[31] Bundesanstalt für Arbeitsschutz und Arbeitsmedizin, "Verordnung über Arbeitsstätten (ArbStättV) - German Regulation for places of work," BGBl. I, Wirtschaftsverlag, Bremerhaven, 2004

[32] VDI 2058 - Part 3, "Beurteilung von Lärm am Arbeitsplatz unter Berücksichtigung unterschiedlicher Tätigkeiten Assessment of noise in the working area with regard to specific operations," Verein Deutscher Ingenieure, Beuth Edition, Düsseldorf, 1999

[33] J. Solet, O. Buxton, A. Carballeira and J. Ellenbogen, "Safe and sound? Sleep disruption in healthcare facilities," J. Acoust. Soc. Am. 125 (4), 2706-2706 (2009)

[34] A. L. Williams, W. Van Drongelen and R. E. Lasky, "Noise in contemporary neonatal intensive care," J. Acoust. Soc. Am. 121 (5), 2681-2690 (2007)

[35] “Guidelines for community noise," edited by B. Berglund, T. Lindvall and D. H. Schwela, Technical Report, World Health Organisation, Geneva, Switzerland 1999

[36] R. E. Lasky, A. L. Williams, W. Van Drongelen and L. C. Gray, "Noise in neonatal intensive care units (NICUs) and its effect on high risk newborns," J. Acoust. Soc. Am. 118 (3), 19561956 (2005)

[37] "Information on levels of environmental noise requisite to protect public health and welfare with an adequate margin of safety" (Report No. 5509-74-004), Environmental Protection Agency, Office of Noise Abatement and Control (Government Printing Office, Washington D.C., 1974).

[38] C. Meredith, J. Edworthy, "Are there too many alarms in the intensive care unit? An overview of the problems," J. of Advanced Nursing 21 (1), 15-21 (1995)

[39] N. P. Mann, R. Haddow, L. Stokes, S. Goodley, N. Rutter, "Effect of night an day on preterm infants in a newborn nursey: randomised trail," Br. Med. J. (Clin. Res. Ed.) 293, 1265-1267

[40] B. Walder, D. Francioli, J. J. Meyer, "Effects of guidlines implementation in a surgical intensive care unit to control nighttime light an noise levels," Critical Care Medicine 28 (7), 2242-2247 (2000)

[41] D. M. Olsen, C. O. Borel, D. T. Laskowitz, D. T. Moore, E. S. Mc Connell, "Quiet time: a nursing intervention to promote sleep in neurocritical care units," Am. J. Crit. Care 10 (2), 74-78 (2001)

[42] V. Bloomkvist, C. A. Eriksen, T. Theorell, R. Ulrich, G. Rasmanis, "Acoustics and psychosocial environment in intensive coronary care," Occup. Environ. Med. 62 (3), electronic version (2005)

[43] A. Richardson, M. Allsop, E. Coghill, C. Turnock, "Earplugs and eye mask: do they improve critical care patients' sleep?," Nursing in Critical Care 12 (6), 278-286 (2007)

[44] C. J. Wallace, J. Robins, L. S. Alvord, J. M. Walker, "The effect of earplugs on sleep measures during exposure to simulated intensive care unit noise," Am. J. Crit. Care 8 (4), 210-219 (1999)

[45] J. W. Williamson, "The effects of ocean sounds on sleep after coronary artery bypass graft surgery," Am. J. Crit. Care 1 (1), 91-97 (1992) 